\title{
Fibrin(ogen)olysis in polymyalgia rheumatica and temporal arteritis: preliminary findings on association with disease activity
}

\author{
RAFAEL G. GRAU, STUART S. KASSAN, JOHN J. FRANKS, \\ HERBERT KAPLAN, STROTHER H. WALKER, AND ENG M. TAN* \\ From the University of Colorado School of Medicine and the Denver VA Medical Center, Denver, CO, USA
}

SUMMARY Postulating an increased production of fibrin(ogen)olytic degradation products (FDP) and an abnormality of fibrinogen metabolism in polymyalgia rheumatica (PMR) and temporal arteritis (TA), we studied $16 \mathrm{PMR} / \mathrm{TA}$ patients and 10 control subjects using a sensitive radioimmunoassay for a specific type of FDP, namely, fibrin(ogen)-related D-antigen. Median serum D-antigen levels were increased five-fold in those 11 PMR/TA patients who were untreated compared with control subjects. In the five PMR/TA patients who were treated with prednisone the median D-antigen levels were not significantly different from those of the healthy controls. D-antigen concentration correlated significantly $(r=0.83)$ with ESR in the seven untreated PMR patients. In PMR patients prednisone therapy was followed by a reduction of serum D-antigen levels.

Polymyalgia rheumatica (PMR) and temporal arteritis (TA) are interrelated clinical syndromes which are often accompanied by giant cell arteritis and a raised erythrocyte sedimentation rate (ESR). ${ }^{12}$ The affected vessels often show thrombosis and luminal narrowing. ${ }^{3}$ These findings in conjunction with elevated fibrinogen levels, ${ }^{45}$ suggest that abnormalities of fibrinogen metabolism may exist, either of pathogenetic significance or as a reflection of the underlying process.

In health most if not all fibrinogen is catabolised by unknown processes, with minimal conversion by thrombin to fibrin or by plasmin to fibrinogen degradation products. ${ }^{67}$ In certain pathological states conversion of fibrinogen to fibrin and proteolysis of fibrin and fibrinogen to fibrin(ogen)olytic degradation products (FDP) occur at a sufficiently rapid rate for specific FDP to be identified in the serum or plasma. A variety of FDP can be isolated. ${ }^{8}$ Among them are two D-antigens, $D_{1}$ (a specific proteolytic product of fibrinogen ${ }^{9}$ or fibrin monomer) and D dimer (a specific cross-linked fibrin product. ${ }^{10}$ We report the use of a sensitive fibrin-

Accepted for publication 19 march 1984.

Correspondence to R. G. Grau, MD, University of Illinois College of Medicine at Peoria, PO Box 1649, Peoria, Il 61656, USA. ${ }^{*}$ Current address, Scripps Clinic and Research Foundation, La Jolla, CA. (ogen) related D-antigen radioimmunoassay ${ }^{11} 12$ capable of estimating serum levels of FDP containing $D_{1}$ and $D$ dimer in a group of PMR or TA patients, either untreated or treated with prednisone, and in normal control subjects.

\section{Materials and methods}

The patients and control subjects were seen in the Arthritis Clinic at the University of Colorado Health Sciences Center. Included were 11 patients with PMR, five with TA, and 10 non-rheumatic control subjects, four of whom had mild osteoarthritis and two mild hypertension.

All PMR and TA patients fulfilled previously outlined criteria. ${ }^{13}$ No PMR patient had historical or clinical evidence of temporal artery inflammation.

Blood samples for fibrin(ogen) related $D$ antigen measurements were collected in tubes containing $3670 \mathrm{NF}$ units of soybean trypsin inhibitor and 20 NIH units of bovine thrombin. Each sample was incubated for two hours at $37^{\circ} \mathrm{C}$ and centrifuged. Serum was removed and stored at $4^{\circ} \mathrm{C}$ for one week or less before assay. Fibrin(ogen) related D antigen was measured by radioimmunoassay by a double antibody technique described previously. ${ }^{11} 12$

Statistical methods. Groups were compared by the 
Kruskal-Wallis test. ${ }^{14}$ If the result of this test was significant, pairwise comparisons were made by the rank-sum test. Results were confirmed by a one-way analysis of variance on a log transformation of the data, followed by Duncan's $\mathrm{k}$ ratio procedure for multiple comparisons. ${ }^{14}$ Association between D antigen concentration and ESR was determined by the Spearman rank correlation coefficient as well as by unranked regression, with comparable results.

\section{Results}

Sixteen patients, 11 PMR and 5 TA (12 females and 4 males), with a median age of 69 (range, 50 to 86), were studied. The median age of the control subjects was 63 (range, 50 to 74) with 9 females and 1 male (Table 1). The median disease duration was 3 months (range 1 to 24 months). Three TA patients had the diagnosis confirmed by biopsy, while two were diagnosed clinically. Four TA patients had a mild preceding or concurrent myalgic syndrome. Five patients, 4 PMR and 1 TA, were receiving prednisone when first studied $(8-40 \mathrm{mg} / \mathrm{day})$. The median ESR of the untreated PMR $(n=7)$ and TA $(\mathrm{n}=4)$ patients was $86 \mathrm{~mm} / \mathrm{h}$ (range, 63-127) and 81 $\mathrm{mm} / \mathrm{h}$ (range, 58-119) respectively. These values differed significantly $(p<0.02)$ from the median ESR of treated PMR/TA patients, which was 19 $\mathrm{mm} / \mathrm{h}$ (range 5 to 41 ), and from the control subjects' median, which was $20 \mathrm{~mm} / \mathrm{h}$ (range 6 to 40 ).

Fig. 1 shows logarithmic plots of individual measurements of $D$ antigen concentration in the various study groups: untreated PMR or TA patients, treated PMR or TA patients, and control subjects. D antigen levels in seven untreated PMR patients (median $3.54 \mu \mathrm{g} / \mathrm{ml}$ ) and four untreated TA patients (median $1.28 \mu \mathrm{g} / \mathrm{ml}$ ) were elevated compared with controls (median $0.49 \mu \mathrm{g} / \mathrm{ml})(\mathrm{p}<0.01)$. $D$-antigen levels were higher in untreated PMR than in untreated TA $(\mathrm{p}<0 \cdot 03)$. (SI conversion: $\mu \mathrm{g} /$ $\mathrm{ml}=\mathrm{mg} / \mathrm{l}$.)

Median concentrations $(\mu \mathrm{g} / \mathrm{ml}$ serum) for the combined 11 untreated PMR and TA patients was

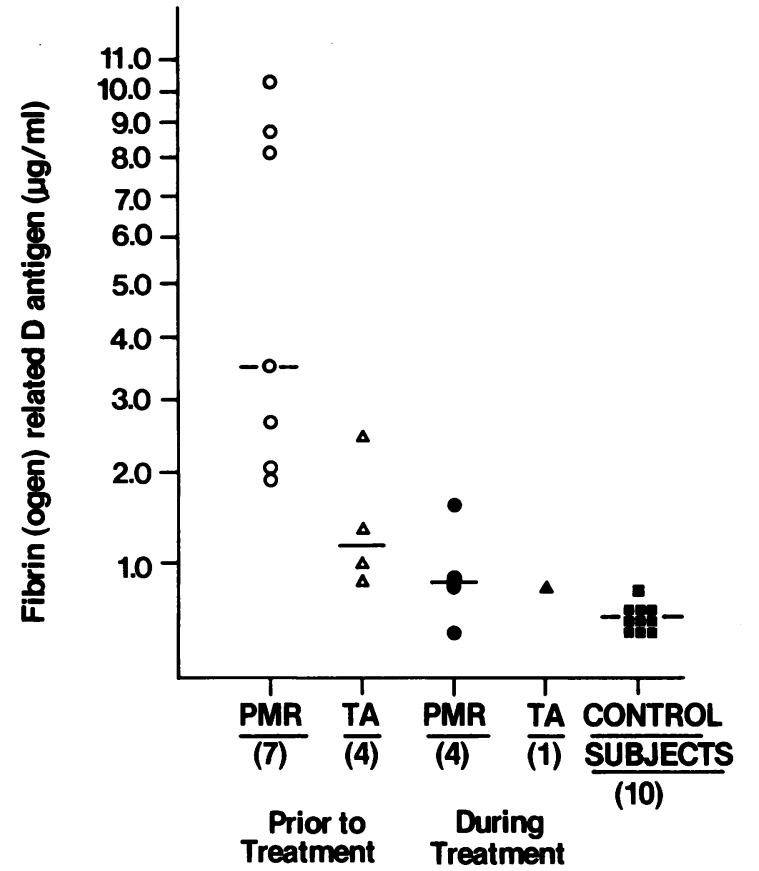

Fig. 1 Logarithmic plot of fibrin(ogen) related $D$ antigen concentration in sera of patients with untreated $P M R(O)$ and $T A(\triangle)$, prednisone treated $P M R(\Theta)$ and $T A(\mathbf{\Delta})$, and control subjects ( $\mathbf{\square}$. Lines indicate the median value of each group. Numbers in parentheses at bottom of figure indicate the number of patients or subjects in each group. Median of untreated PMR/TA patients differs significantly $(p<0.01)$ from medians of treated PMR/TA patients and control subjects. Also the medians of untreated PMR patients differs significantly $(p<0.03)$ from median of untreated TA patients. Statistical methods are described in the text.

2.45 and for the five treated PMR and TA patients was 0.77 , compared with 0.49 for the controls. Differences between untreated patients and either treated patients or control subjects were significant $(\mathrm{p}<0 \cdot 01)$, but treated patients did not differ significantly from controls.

Table 1 Clinical and therapeutic data on 16 patients with polymyalgia rheumatica and temporal arteritis

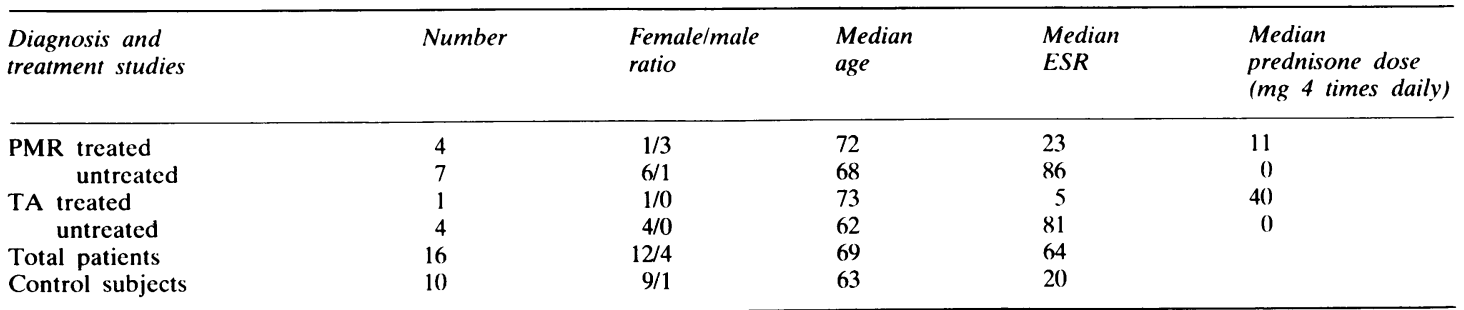

PMR = Polymyalgia rheumatica. $\mathrm{TA}=$ Temporal arteritis. 


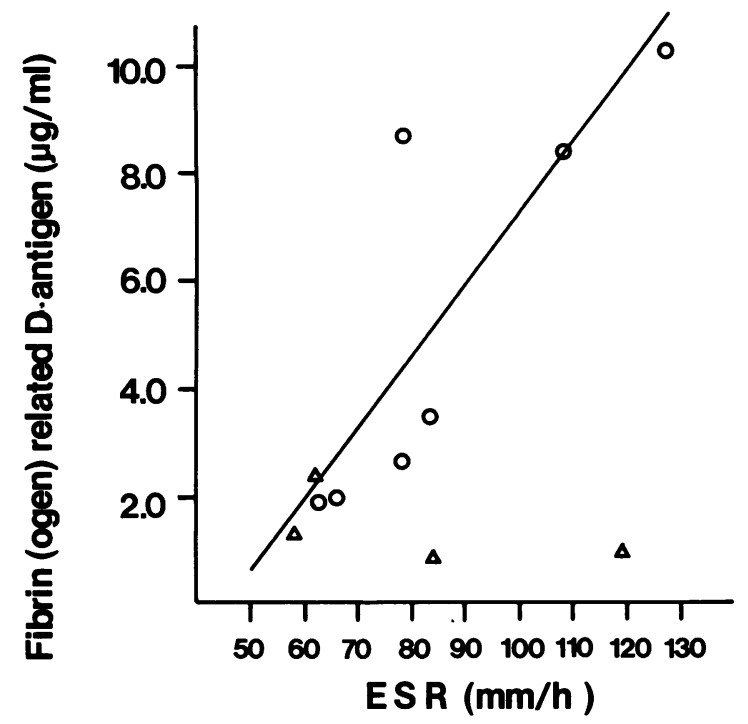

Fig. 2 Regression of serum concentration of fibrin(ogen) related $D$ antigen (FRDA) on Westergren erythrocyte sedimentation rate (ESR) in 7 patients with untreated $P M R$ (O). Significant correlation was observed $(r=0 \cdot 83$, $p<0.01)$. Lack of correlation between FRDA concentration and ESR in four patients with untreated TA $(\triangle)$ is evident. Statistical methods are described in the text.

Three PMR patients were studied before and after treatment with prednisone for one to three months. In each of these patients treatment resulted in a drop in $\mathrm{D}$ antigen concentration toward normal, the initial median level being $2.26 \mu \mathrm{g} / \mathrm{ml}$ and the subsequent one $1.21 \mu \mathrm{g} / \mathrm{ml}$.

Significant correlation was observed between D antigen levels and ESR in the seven untreated PMR patients $(r=0 \cdot 83, p<0 \cdot 01)$. No such correlation was found in the four untreated TA patients (Fig. 2).

\section{Discussion}

The fibrin(ogen)-related D-antigen measured by radioimmunoassay in our patients with PMR or TA cannot definitely be identified as fibrin fragment $\mathrm{D}$ dimer, because anti-D dimer rabbit globulin reacts with the $\mathrm{D}$ domain of fibrinogen and of fibrinogen fragments $X, Y$, and $D_{1}$ as well. However, antibody affinity for these latter substances is only about $10 \%$ that of an equivalent amount of $\mathrm{D}$ dimer. In addition the assay dilution curves of patient (and control) sera were parallel to the $\mathrm{D}$ dimer standard curves. Parallelism of assay dilution curves is a necessary, though not a sufficient, condition to establish identity. The evidence suggests that most of the FDP found with our assay in patients with
PMR or TA is fibrin fragment D dimer, either free or complexed with other fibrinogen moieties.

$\mathrm{D}$ antigen concentrations in our healthy subjects and patients varied from about 0.4 to $10 \mu \mathrm{g} / \mathrm{ml}$. Our results correspond closely with values seen in control and postoperative subjects $(0 \cdot 86$ to $10 \cdot 1$ $\mu \mathrm{g} / \mathrm{ml}$ ) using a different fibrinogen fragment $\mathrm{D}$ assay. ${ }^{15}$ These values are lower than those obtained by other tests, in which FDP levels ranging from 12 to over $1000 \mu \mathrm{g} / \mathrm{ml}$ were found in a variety of acute and subacute conditions. ${ }^{16}{ }^{17}$ However, those patients presented with a manifest defibrination syndrome and might be expected to produce larger amounts of FDP than patients with PMR or TA.

While fibrinogen levels are increased in untreated PMR or TA patients, it seems unlikely that their high $\mathrm{D}$ dimer concentrations merely reflect the fibrinogen increment. In fact the converse may be operating. Rats injected with homologous $D_{1}$ or isolated rat livers perfused with blood from traumatised rats (which contains high levels of $D$ antigens) respond by increasing their rates of fibrinogen synthesis. ${ }^{18} 19$

Fibrinogen/fibrin deposits have been found in the capillary walls of deltoid muscle biopsies in PMR patients. ${ }^{20}$ In addition thrombi have been noted in temporal artery biopsies with proved giant cell arteritis. ${ }^{6}$ It is conceivable, therefore, that PMR and TA are associated with local fibrin formation and lysis within affected vessels, perhaps because of release of activators from the altered vascular endothelium. Indeed, in-vitro cytotoxicity of sera from PMR and TA patients to human endothelial cells has been described. ${ }^{21}$ The raised levels of FDP may indicate enhanced thrombin or plasmin (or, less likely, other proteolytic enzyme) activity. Whether the elevated D antigen concentrations represent a primary pathogenetic process or merely reflect vascular inflammation and subsequent fibrin formation and lysis is unclear.

Supported by the Medical Research Service of the United States Veterans Administration. NIH grant AM 20705, and grant number RR-00051 from the General Clinical Research Centers Program of the NIH Division of Research Resources.

\section{References}

1 Fauchwald P, Rygvold O, Oystese B. Temporal arteritis and polymyalgia rheumatica. Ann Intern Med 1972; 77: 845-52.

2 Hunder G E, Disney F F, Ward L E. Polymyalgia rheumatica. Mayo Clin Proc 1969; 44: 849-75.

3 Hamilton C R Jr, Shelley W M, Tumulty P H. Giant cell arteritis: including temporal arteritis and polymyalgia rheumatica. Medicine (Baltimore) 1971: 50: 1-17.

4 Bagratuni L. Plasma proteins and cryoglobulins in anarthritic rheumatic disease. Ann Rheum Dis 1957; 16: 104-10. 
5 Wilske K R. Healy L A. Polvmvalgia rheumatica. A manifestation of svstemic giant cell arteritis. Ann Intern Med 1967; 66: $77-86$

6 Reeve E B. Franks J J. Fibrinogen sunthesis. distribution and degradation. Semin Thromb Hemostas 1974: 1: 129-83.

7 Collen D. Semeraro N. Verstraete M. The fibrinogenolytic pathwav of fibrinogen catabolism: a replv. Thromb Res 1974; 4: $49 !-6$.

8 Merskev C. Johnson A J. Harris J U. Wang M T. Swain S Isolation of fibrinogen-fibrin related antigen from human plasma bv immunoaffinitv chromatography: its characterization in normal subjects and in defribinating patients with abruptio placentac and disseminated cancer. Br J Haematol 1980: 44: $655-70$.

9 Marder V J. Shulman N R. Carrol W R. High molecular weight derivations of human fibrinogen produced by plasmin. $J$ Biol Chem 1969: 244: 2111-4

1) Gaffney P J. Brasher M. Subunit structure of the plasmininduced degradation products of crosslinked fibrin. Biochim Biophes Acta 1973: 295: 30k-13

11 Hvers T M. Martin B J. Pratt D S. Dreisin R B. Franks J J. Thrombin and plasmin activitv with exercise in man. J Appl Physiol 1980: 48: $821-5$.

12 Havnes B J. Hvers T M. Giclos P C. Franks J J. Petty T L. Elevated fibrinogen/fibrin-derived degradation products in the adult respiratory distress svndrome. Am Rev Resp Dis 1980: 122: $841-8$.
13 Bengtsson B A. Malmvall B O. The epidemiology of giant cell arteritis including temporal arteritis and polvmyalgia rheumatica. Arthritis Rheum 1981; 24: 899-9()4.

14 Snedecor G W. Cochran W G. Statistical methods. 7th ed. Iowa State University Press, 1980.

15 Gordon Y B. Martin M J. McNeile A T. Chard T. Specific and sensitive determination of fibrinogen-degradation by radioimmunoassay. Lancet 1973; ii: 1168-70.

16 Merskey C. Lalezari P. Johnson A J. A rapid, simple, sensitive method for measuring fibrinolvtic split products in human serum. Proc Soc Exp Biol Med 1969: 131: 871-5.

17 Merskey C. Johnson A J. Kleiner G J. Wohl H. The defibrination syndrome: clinical features and laboratory diagnosis. Br J Haematol 1967: 13: 528-49.

18 Franks J J, Kirsch R E. Frith L O, et al. Effect of fibrinogenolytic products $D$ and $E$ on fibrinogen and albumin synthesis in the rat. J Clin Invest 1981: 67: 575-80.

19 Kirsch R E. Franks J J. Fibrinogen synthesis in the isolated perfused rat liver: stimulation by a humoral factor associated trauma. Hepatology 1982: 2: 205-8.

20 Rynes R I. Hanson P A, Urizar R E. Zdeb M S. Histologic abnormalities in polymyalgia rhcumatica (PMR). Arthritis Rheum 1980; 23: 741.

21 Bocanegra T S. Germain B F. Saba H I. et al. In vitro crtotoxicity of human endothelial cells in polymyalgia rheumatica and giant cell arteritis. Rheumatol Int 1982; 2: 133-6. 